\title{
Domesticative Selection for Low Prolificacy and High Harvestability and Mutability Led to Evolution of Modern Maize from Wild Teosinte: A Brief Review of the New Genetic, Genomic and Archaeological Evidence
} SUSHIL KUMAR ${ }^{1,2, *}$, RENU KUMARI ${ }^{1}$ and VISHAKHA SHARMA ${ }^{3}$

${ }^{1}$ National Institute of Plant Genome Research (NIPGR), Aruna Asaf Ali Marg, New Delhi 110 067; ${ }^{2} S K A$ Institution for Research, Education and Development (SKAIRED), 4/11 Sarv Priya Vihar, New Delhi 110 016, and ${ }^{3}$ University Innovation Center, Jayoti Vidyapeeth Women's University, Jaipur 305001

(Received on 28 May 2019; Revised on 28 January 2020; Accepted on 8 September 2020)

\begin{abstract}
Maize/corn (Zea mays subspecies mays), the most productive cereal food crop was domesticated, progressively, 90004000 years ago in the Mexican and Amazonian regions of South America. Archaeological, genetic and genomic evidence shows that a genotype of teosinte (Zea mays subspecies parviglumis, the progenitor of maize), in which many desirable traits got recombined and made the plant produce plentiful of easily harvestable and directly consumable grains in a small number of cobs (low prolificacy), was selected and evolved into the modern maize crop. The selected genotype carried on its genome mutant alleles in atleast 1000 genes; however, among them a small number of loci produced very large effects. The large effect alleles, identified to have led to maize domestication, are teosinte branched 1 (tb1), teosinte glume architecture 1 (tgal), grassy tillers (gtl), tassels replace uppers-ears 1 (trul), ramosa 1 (ral), zeafloricaula leafy 2 (zfl2), zfl 1 , zeaagamous-like 1 (zagll), shattering 1 (shl) and atr (ataxia telangiectasia and rad 3 related). All the major effect alleles, except atr, being in transcription factor encoding genes, apparently the functions of their downstream genes determined the maize domestication traits. The downstream gene network of $t b 1$ has been partially catalogued. TB1 represses certain cell cycle genes, and activates gt1, trul and tgal. TGA1 represses a small number of MADS-box transcription factor genes. ATR regulates DNA damage response mechanisms by activating the products of several downstream DNA repair proteins/ enzymes. TB1and GT1 activate the pathways for synthesis of abscicic acid and jasmonic acid, suppress that for gibberellins and reduce sugar levels and energy balance. The downstream network of $g t 1$ remains largely unknown and networks of $t b 1$ and tgal are not fully characterized. Need is emphasized for the analyses of all the maize loci that affected domestication via their mutagenesis (random and CRISPER systems directed), over-expression transgenosis and RNAi interference, and expression of the resulting variants in all the organs, under varying environments. Imperativeness of the information so gained in the directed improvement of agronomic features of maize and other parallelly domesticated cereals is pointed out.
\end{abstract}

Keywords: Maize domestication; Grassy Tillers 1; Ramosa 1; Shattering 1; Tassels Replace Upper-Ears 1; Teosinte Branched 1; Teosinte Glume Architecture 1; Zea Floricaula LEAFY 2; Ataxia Telangiectasia and RAD3 Related

\section{Introduction}

Maize (or modern maize, family Poaceae, tribe Andropogoneae; $2 \mathrm{n}=20$, genome size $2500 \mathrm{Mb}$; GC content $47.4 \%$ ) is a staple crop, used as source of fluor and oil, industrial raw materials such as syrup, ethanol and plastic and feed for livestock. In 2018, world's maize grain production was 1068 million tons,
26 million tons in India. Together with rice and wheat, maize meets $\sim 70 \%$ of world's food consumption. With its genome carrying 35,000 protein coding genes, many more non-coding genes and 1,30,604 intact transposable elements, maize is serving as a model for breeding, genetics and genomics among crop plants (Wang et al., 2016; Jiao et al., 2017; Yang et al., 2019).

*Author for Correspondence: E-mail: sushil2000_01@yahoo.co.in 
Modern maize was domesticated 9000-4000 years ago (ya) from teosinte; it now occupies a status of subspecies (Zea mays ssp. mays) distinctly morphologically diverged from the parental subspecies teosinte (Zea mays ssp. parviglumis). Modern maize and teosinte are members of the same species, because maize continues to carry many features of teosinte and can be crossed with it. Origin of maize in South America, from the wild populations of teosinte, involved progressive selection of naturally occurring morphological mutations of economic importance and their recombinants. Early domesticated maize differed from wild type teosinte, most importantly, in being unbranched, and bearing only a few large ears/cobs and on them disarticulatory naked grains.

Evolution of modern maize has been investigated intensively since the early studies of Manglesdorf and Reeves (1938) and Beadle (1939), using a variety of genetic- and genomic- procedures on the landraces of teosinte, landraces and accessions/ cultivars of maize and archaeological specimens of the evolving maize recovered in Americas. Several genes whose variant alleles were selected during teosinte/maize domestication have been identified, but many loci found associated with the domestication remain to be annotated. The timeframe and geographical areas of maize domestication have been largely elucidated. This review briefly illuminates the morphological traits that distinguish teosinte and maize, summarizes the archaeogenetic studies which define the times and geography of major domestication events and identifies a network of genes and loci whose mutant alleles got recombined and selected in domesticated maize and nucleotide content changes, as revealed by genetic and genomic studies. It also identifies subject areas of research deficit which need to be pursued in future.

\section{Genetic Morphological Differences Between Wild Teosinte and Modern Maize that Decreased Prolificacy and Increased Harvestability in Maize}

Both teosinte and maize are monoecious; they are interfertile and possess self-cum-cross pollinated reproductive system. The phenotype of modern maize differs from its teosinte parent in many traits, but five of these are of major importance whose selection made maize a high yielding grain crop. These relate to shoot architecture, fertility of spikelets, phyllotaxy and sturdiness of female inflorescence and nakedness of kernels/grains/seeds. The differences for these characters between teosinte and maize are briefly described in the table 1 and depicted in the Fig. 1. The maize alleles that determine the domesticated traits are also identified in Table 1.

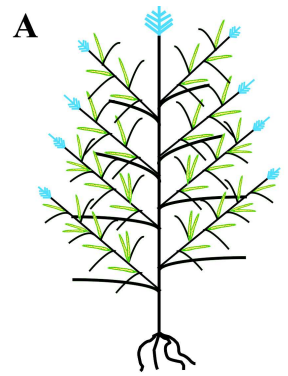

B

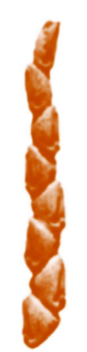

$\mathbf{E}$

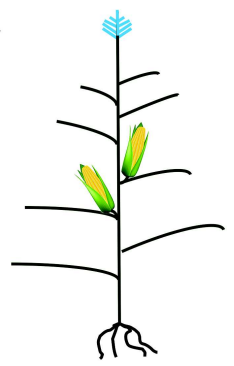

F

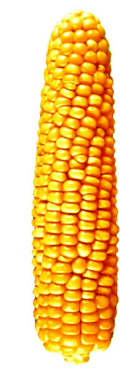

C

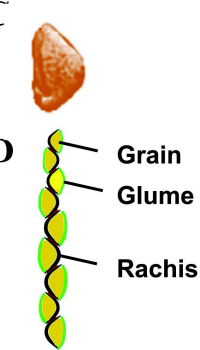

G

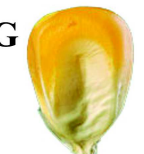

$\mathbf{H}$

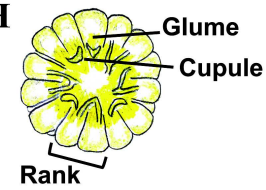

Fig. 1: Diagrammes and pictures of teosinte and maize plants and organs showing differences in plant and female inflorescence architectures and kernels (seeds). Female inflorescences (ears) and kernels are shown in yellow or brown colour and male inflorescences in blue colour. A, a plant of teosinte (Zea mays ssp. parviglumis); B, an ear of teosinte bearing 7 kernel containing fruitcases arranged in distichous phyllotaxy; C, a seed containing fruitcase of teosinte; $D$, longitudinally sectioned ear of teosinte in which a grain is seen enveloped inside the fruitcase consisting of glume and a part of rachis (cupule); E, a plant of maize (Zea mays ssp. mays); F, an ear/cob of maize; G, a seed of maize which is naturally devoid of any envelope; $H$, a transverse section of maize cob in which the central axis consisting of ear rachis (cupules) and glumes bears on the circumference 14 rows ( 7 ranks) of seeds; $F$ and $H$, demonstrate polystichousphyllotaxy of maize cob

The teosinte plants are gigantic by being massively branched. Each node of the main stem bears a long lateral stem and the main and lateral stems are tipped by a tassel each. All nodes of lateral stems bear an ear, which may be simple or branched; altogether a teosinte plant has on it more than 100 ears. Like in all Andropogoneae species, teosinte ear bears pairs of spikelets on its rachis, however, one of 
Table 1: Principal morphological differences between modern maize and wild teosinte, the parent from which maize evolved by domestication. The major genes/loci whose spontaneous mutant alleles underwent artificial selection and recombined during domestication are also identified

\begin{tabular}{|c|c|c|c|c|c|}
\hline S. no. & Trait $^{\mathrm{a}}$ & $\begin{array}{l}\text { Phenotype in teosinte } \\
\text { (Zea mays ssp parviglumis) }\end{array}$ & $\begin{array}{l}\text { Phenotype in modern } \\
\text { maize (Zea mays ssp. mays) }\end{array}$ & $\begin{array}{l}\text { Gene(s)/ locus (loci) whose mutant alleles } \\
\text { determine inheritance of maize phenotype }\end{array}$ & References \\
\hline 1 & $\begin{array}{l}\text { Shoot } \\
\text { architecture }\end{array}$ & $\begin{array}{l}\text { Main stem bears a number } \\
\text { of lateral branches (tillers). } \\
\text { Each branch is tipped by a } \\
\text { tassel. Nodes on branches } \\
\text { bear one or more ears } \\
\text { (female inflorescences). } \\
\text { There can be more than } 100 \\
\text { ear inflorescences on a plant }\end{array}$ & $\begin{array}{l}\text { Main stem has little tillering } \\
\text { and is tipped by a tassel. } \\
\text { One and rarely two upper } \\
\text { nodes of stem form a branch } \\
\text { each of which is tipped } \\
\text { by an ear (cob) }\end{array}$ & $\begin{array}{l}\text { Reduction in tillering results from apical dominance induced } \\
\text { by the mutant form of teosinte branching } 1 \text { ( } t b 1) \text { gene whose } \\
\text { expression is enhanced by insertion of Hopscotch transpo- } \\
\text { sable element } 65 \mathrm{~kb} \text { upstream of } t b 1 \text { ORF. Mutation in } \\
\text { grassy tillers } 1 \text { ( } \mathrm{gt} 1 \text { ) gene reduces the number and increases } \\
\text { the size of ear(s). Mutation in tassels replace upper ears } 1 \\
\text { (trul) gene controls bud dormancy and therefore aerial } \\
\text { branch outgrowth. Expression of } t b 1 \text {, trul and gt } 1 \text { is } \\
\text { modulated by a number of genes which remain to be } \\
\text { annotated }\end{array}$ & $\begin{array}{l}\text { Doebley and Iltis 1980; Iltis and } \\
\text { Doebley 1980; Doebley et al. 1995; } \\
\text { Doebley et al. 1997; Dong et al. 2019; } \\
\text { Studer and Doebley 2011 and 2017; } \\
\text { Whipple et al. 2011; Wills } \text { et al. } 2013 \\
\text { and 2018; Flint-Garcia } 2017\end{array}$ \\
\hline
\end{tabular}

2 Spikelet One of the pair has aborted Both spikelets of the pair pairs on development, therefore only form a kernel(seed) each rachis in one spikelet forms seed female

inflorescence

3 Phyllotaxy of Succeeding nodes of rachis female alternately bear a grain inflorescence forming one spikelet (distichous phyllotaxy). The spike (ear) bears 5-12 grains; grains are small in size (one tength of that of maize kernel)

The phenotype is controlled by ramosa 1 ( ral); other genes Doebley and Stec 1991 and 1993; that are involved and are located on chromosomes Doebley et al. 1995; Vollbrecht 1, 2, 3, 4 and 10 remain to be annotated et al. 2005; Sigmon and Vollbrecht 2010

Phyllotaxy is polystichous; Zea floricaula leafy 2 (zfl2), zfl1, zea agamous-like (zagl 1), Doebley and Stec 1991 and 1993 ; it is whorlled such that upto and several yet to be annotated genes located on Bomblies and Doebley 2006; 10 ranks of spikelet pairs chromosomes $1,3,4,5,9$ and 10 are involved (or 20 grains) are formed simultaneously on ear

because of collapse of internodes which become a part of the ear axis. There can be several hundred $(<800)$ kernels per cob Inflorescence is sturdy, fully mature-dry kernels remain attached to cob

Shattering 1 duplicates, including sh1-1, sh $1-5$, and sh1-5.2, are involved Briggs et al. 2007; Brown et al. 2011; Wills et al. 2013 and 2018

since rachis has non-

disarticulating nature

Kernels are exposed because Teosinte Glume Architecture 1 (TGA1), itself positively cupule is reduced and glume regulated by $t b l$, is involved; it regulates many genes, is small and papery, and

both glume and cupule are a part of cob's axis which is hard

Higher mutation rate due to errors in nucleotide excision repair of solar UV-damage to DNA including those determining the non-disarticulating rachis and polystichous phyllotaxy

Mutated ATR (Ataxia Telangiectasia and RAD3 Related) protein gene, which is a regulator of DNA damage response, genecards.org/cgi-bin/carddisp.pl? enceases homologous recombination repair frequency and $=$ ATR thereby induction of errors in DNA sequence

a: Modern maize and wild teosinte differ in a number of physiological traits, including that teosinte is a short day plant and its seeds enter dormancy, contrastingly maize flowering is photoperiod independent (Minow et al., 2018) and maize seeds do not enter dormancy (Avendano Lopez et al., 2011) 
them aborts and only one develops into a seed. Thus on account of distichous phyllotaxis teosinte ear has up to a dozen kernels. Each kernel/grain is enveloped in silica and lignin containing hard fruitcase formed by glume and a part of rachis called cupule, much like a walnut or pistachio nut, which upon maturity drops from the inflorescence for dispersal. Grains/seeds of teosinte are difficult to harvest and consume by humans. Maize plants are single stemmed, main stem is tipped by a tassel. The axils of one or two leaves on the stem bear an ear each. When a maize plant has two ears, both ears mature nearly synchronously, making the cob harvesting convenient. Maize ear has polystichous or whorled phyllotaxy. Multiple spikelet pairs are formed on closely located ear nodes as if produced simultaneously. Thus an ear/cob of maize has up to 1000 seeds arranged in 2 to $>20$ rows around hard central axis formed by ear axis (cupules) and glumes. The maize seeds are not enveloped and do not disarticulate from the cob spontaneously. The nakedness of grains make them directly usable. Briefly, in the domesticated maize, plants are smaller and easier to harvest than in teosinte. Selection for domestication (domesticative selection) led to larger grains and large ears but overall edible biomass did not change.

\section{Time and Place of Teosinte Domestication into Modern Maize: Archaeogenomic Findings}

Genomic studies on ancient cobs recovered as macro fossils and land races of two annual teosinte subspecies, namely Zea mays ssp. parviglumis and Zea mays ssp. maxicana(hereafter simply called as parviglumis and maxicana, respectively), and maize, and cultivars of maize have established (Matsuoka et al., 2002; Zeder et al., 2006; Piperno et al., 2009 and 2014; Wang et al., 2015; Ramos-Madrigal et al., 2016; Kistler et al., 2018) that the origin of modern maize began with one domestication event from parviglumis in southwest Mexico. The so evolved proto-maize then spread to different parts of Mexico and South America and gradually evolved into modern maize. Fossilized proto-maize and maize cobs from the period 6250 to 4300 years BP have proved useful material in understanding the aspects of domestication process.

Morphology and dating of archaeological ears/ cobs recovered in GuidaNaquitz cave in Oaxaca,
Mexico show that teosinte had been domesticated earlier than 6250 (6280-6210) ya (Piperno and Flannery 2001). Microsatellite genotyping based phylogenetic analysis on 193 maize accessions from all over Americas of the 500 years BP-period and 67 teosinte accessions from Mexico revealed that parviglumis and maize diverged 9188 years BP in Mexico. It was further concluded that the Balsas River Valley region (a lowland area) of Mexico, wherein parviglumis demonstrates maximum genetic variability, is the place of initial teosinte domestication event(s) exercised by the local nomadic farmers (Matsuoka et al., 2002). Comparison of genomic sequences of a 5310 years old maize cob excavated in Tehuacan Valley in Mexico (located 450 kilometers northeast of Balsas River Valley) with those of 23 modern maize landraces and 15 parviglumis and 2 mexicana accessions showed that by 5300 years BP proto-maize carried the tgal allele of maize for soft and naked kernels, but the zagl 1 allele, which determines the disarticulating ear character, was of parviglumis type. The cobs of this proto-maize were $\geq 2 \mathrm{~cm}$ long and carried 8 rows of kernels. The Tahuacan proto-maize was found to be more closely related to parviglumis than to mexicana, although there were signs of introgression with the latter. Both parviglumis and mexicana occur sympatrically in the lower and higher altitudes of Balsas River Valley. It is now known that maize obtained $\sim 10 \%$ of its genetic content from mexicana. The slow pace of domestication in Mexico evidenced by macro-fossils has been attributed to low levels of natural backcrossing between proto-maize and parviglumis (Ramos-Madrigal et al., 2016; Lu et al., 2019).

The domestication of proto-maize into modern maize proceeded in Mexico, as well as in parts of south America. Kistler et al. (2018) compared genomes of 40 maize landraces indigenous to south America, with those of 68 modern and 9 archaeological maize and 2 ancient parviglumis, published earlier. The study showed that proto-maize was under cultivation in southern Amazon region (present Brazil and Bolivia) 6500 ya. Cobs of 4300 ya maize recovered in El-GigenteRockshelter in Honduras, located on southern side of Mexico, were bearing 1014 rows of kernels, like in many maize land races (Kennet et al., 2017). The archaeological references collated by Bush et al. (1989) and Kistler et al. (2018) indicate that the monophyletic proto-maize, developed 
by selection of rare recombinants between teosinte plants carrying useful traits by Balsas River Valley farmers in Mexico 9000 ya, was being cultivated widely in Mexico and its produce had spread by trade southwards widely atleast 7500 ya onwards. While proto-maize genotypes of varying morphology were being cultivated in different areas of central and southwestern America, advanced recombinants of the agriculturally useful traits were being selected and fixed. This activity was especially prominent in the Amazon region where wild annual teosinte were largely absent. It appears that the modern maize like genotypes had emerged in several areas of south America by 4000 ya. Modern maize reached western north America (USA) 3200 ya, eastern USA 2100 ya and Canada 700 ya (Janicke-Despres et al., 2003; Kistler et al., 2018; Stitzer and Ross-Ibarra 2018).

\section{Discovery of Maize Alleles of Some Major Effect Genes whose Selection Reduced Branching, Increased Seed Size And Improved Harvestability}

Modern maize and its ancestor parviglumis teosinte are highly diverged phenotypically and yet belong to the same species because of high gametophytic compatibility between them. Among the many differences between maize and teosinte, the five major morphological changes that led to their classification as distinct subspecies of Zea mays have been briefly described in the section 2 above with reference to Table 1. Since the work of Beadle (1939), a number of studies using a spectrum of genetic and genomic approaches, on genetically diverse maize and teosinte landraces/varieties from all over Americas, have revealed following as the genetic basis of subspeciation. Maize evolved by selection of alleles with major effect at a small number of genes together with compatible allelic changes in moderate and small effect genes that interact with major effect genes/ alleles. Higher level of mutability in the proto-maize populations undergoing domestication had a deterministic role. The forward genetic studies of inheritance of domestication traits showed that each of the five morphological traits that distinguish maize from teosinte is determined by few to many genomic regions spread across all the 10 chromosomes. The comparative genomical studies that scanned the genomes of maize and teosinte variants, to identify the signatures of selection, showed that atleast 1000 genes (or $2-5 \%$ genome) were targeted by domesticative selection (Doebley and Stec 1991 and 1993; Vigouroux et al., 2002; Briggs et al. 2007; Hulfard et al., 2012; Lemmon and Doebley 2014; Studor et al., 2017). Whereas the selection was focussed on ear architecture, the correlated response led to change in plant architecture (Yang et al., 2019). The lessons from hitherto genetic information on the large effect mutant alleles selected to attain the maize domestication traits are gene-wise summarized hereunder. The bulk of the downstream genes whose mutant alleles got selected for their compatible interaction with large effect mutant alleles remain to be elucidated.

\section{Teosinte Branched 1, Grassy Tillers 1 and Tassels Replace Upper-Ears 1}

In maize, suppression of prolificacy and formation of one or two large ears bearing bold kernels is determined by domestication (or domesticative) alleles of the genes teosinte branched 1 ( $t b 1)$, grassy tillers 1 (gtl) and tassels replace upper-ears 1 (trul). The gene $t b 1$, located on chromosome 1 , is one of the apical dominance regulators which suppresses lateral branching that could arise from outgrowth of axillary buds formed on the main stem. It encodes a cycloidea type class II TCP protein domain containing transcription factor that binds to promoters on account of its basic-helix-loop-helix structure (Kosugi and Ohashi 2002). There is overexpression of the TB1 protein from its maize allele because of insertion of a Hopscotch insertion (transposable) element $63 \mathrm{~kb}$ upstream of $t b 1$ start codon. The enhanced expression of TB1 in nodal plexus is the cause of inhibition of lateral branching in maize plants. There is evidence from the genomic studies that the maize allele at $t b 1$ mutated 28,000 ya (Studeret al. 2015). The gene gt 1 also contributes to apical dominance in maize and thus allows formation of only one or two ears per plant which bear heavy seeds. It functions downstream of $t b 1$. The gtl gene located on the short arm of chromosome 1 encodes a homeodomain zipper transcription factor. The maize $g t l$ allele has a 2.72 $\mathrm{kb}$ prolificacy (prol 1.1) sequence $7.5 \mathrm{~kb}$ upstream of its first codon that allows overexpression of GT1 protein in maize plant's main stem nodes such that meristematic growth in large majority of them is inhibited. The maize $g t 1$ allele arose 13,000 ya (Wills et al., 2013 and 2018). The gene trul, located on the long arm of chromosome 3 , which encodes an ankyrin 
repeat domain protein containing a $\mathrm{BTB} / \mathrm{POZ}$ motif, is activated by TB1 for ectopic expression in axillary branches. TRU1 inhibits axillary branch growth and promotes formation of female flowers (Dong et al. 2017).

\section{Ramosa 1}

Maize cobs bear kernels in straight rows. This phenotype results from development and growth of both of the spikelets initiated on the nodes of maize ear. Selection of this domestication trait is related to mutations in the cis-regulatory region(s) of the domestication locus ramosa 1 (ral) gene located on chromosome 7 . The selected mutation(s) permit increased expression of ral, a $\mathrm{C} 2 \mathrm{H} 2 \mathrm{EPF}$-subclass zinc finger transcription factor, involved in the regulation of the genes determining female inflorescence architecture (Vollbrecht et al., 2005; Sigmon and Vollbrecht 2010).

\section{Zea Floricaula Leafy 2 and Zea Agamous-Like 1}

The architecture of maize cobs/ears underwent domesticative selection for high yield via high kernel/ grain number. Spiral phyllotaxy in maize cobs allows 4-10 ranks and therefore 8-20 kernal row number. Among the candidate loci located on chromosomes $1,2,3,4,5,9$ and 10 that show signatures of selection in the determination of high kernel row number, two have been identified as the zeafloricaula leafy 2 $\left(\begin{array}{ll}z f l & 2\end{array}\right)$ gene located on chromosome 2 and zeaagamous-like 1 (zagll) gene located on short arm of chromosome 1. Both specify transcription factors: the $z f l 2$ gene product is FLORICULA/ LEAFY type of transcription factor and the product of zagl 1 gene is a MADS-box transcription factor. Both selected maize mutant alleles express the gene products at increased levels because the mutations occurred in their cis-regulatory regions (Doebley and Stec 1991 and 1993; Bomblies and Doebley 2006; Brown et al., 2011; Wills et al., 2013 and 2018). The maize alleles $z a g l l$ and $z f l 2$ have also been implicated in early flowering (Bomblies and Dobley 2006; Wills et al., 2018).

\section{Zea mays Shattering 1 Orthologues}

Non-shattering of kernels from mature ears/cobs was also a strongly selected trait in maize domestication. Domestication process selected alleles of the YABBY transcription factor coding zm shattering 1-1 (zmsh 1-1) gene located on chromosome 1 and the orthologous zmsh 1.5-1+zmsh 1.5-2 genes located on chromosome 5 which underwent insertional mutations that disrupted their code (Lin et al., 2012). There is some evidence that the loss-of-function allele got selected also for another YABBY class transcription factor gene $z m Y A B 2.1$ located on chromosome 1, for the attainment of non-shattering phenotype in maize (Yang et al., 2016)

\section{Teosinte Glume Architecture 1}

Maize domestication involved selection for its plant type that produced only a few cobs on which naked kernels got formed on the circumference of their hardnon-disarticulating central rachis, such that kernels got arranged in polystichous phyllotaxy on the rachis. The kernel containing 7-12 fruit cases of teosinte, formed by combination of hardened glume and cupule of spikelet, and the rachis bearing them were repurposed by domesticative selection into the central axis of cob in maize to bear many naked kernels of big size. A non-synonymous mutation in the exon 1 of teosinte glume architecture 1 (tgal) gene located on chromosome 4, selected during maize domestication, contributed to all the above mentioned useful traits of maize, including large size, shape and nakedness of kernels, sturdiness and spinal phyllotaxy of cob and reduction in lateral branching leading to formation of 1 or 2 cobs. The mutation changed the property of TGA1 protein from being a gene activator to that of a gene repressor. The maize TGA1 protein, a squamosal promoter-binding (SBP-Box) transcription factor, having undergone mutation acquired a property of forming stable dimers. No lossof-function mutation is known in maize tgal gene. The maize tgal allele arose about 10,000 ya (Preston et al., 2012; Wang et al., 2012 and 2015).

The following salient-points emerge from the above catalogue of the major-effect maize domestication genes: $t b 1$, gtl, trul, ral, zfl2, zagll, sh1, and tgal. (i) All of the major effect domesticative alleles are in genes encoding transcription factors. (ii) The maize mutant alleles in $t b 1, g t 1, t r u 1, z f l 2$ and tgal have effect on seemingly unrelated phenotypes or are pleiotropic. (iii) The domesticative alleles in $t b 1, g t 1, r a l, z f l 2$ and zagll increased the gene expression, mainly by use of cis elements present 
in transposon inserted 5' to the gene's open reading frames. Thus a highly significant role of transposable elements, that comprise e" $85 \%$ of maize genome, is testified in the evolution of modern maize. (iv) A point/ transversion mutation in maize tgal gene converted the product from being a gene activator into a gene repressor. (v) The transcription factor products of $s h 1$ genes became non-functional due to incorporation of loss-of-function mutation in their maize alleles. Altogether, it is clear that all the major effect domestication genes in maize produce their effect via the functions of downstream genes targeted by them. To understand the gene expression changes that mediate the phenotype of modern maize, it is imperative that the gene network of each of the above identified transcription factors genes be catalogued function-wise. Some progress that has been made in elucidation of the network of genes whose expression is controlled by $t b 1$ is summarized below.

\section{Gene Network Targeted by the Maize tb1 Allele}

The maize allele of $t b l$ gene selected during domestication is a master regulator that is known to control a cascade of transcription factors and certain cell cycle genes, that determine development and morphology of plant's shoot, root, female inflorescence, flower and seed, pleiotropically. In the course of domestication the multitude of transcription factors controlled by $t b 1$ or by gene(s) downstream of $t b 1$ also underwent mutant allele selection, for adaptation to genetic changes in their regulatory or interactive genes. The network of genes, thus far known to be interactive with the maize $t b 1$ allele (Studer et al. 2017; Dong et al. 2019) is diagrammed in Fig. 2.

The master transcription factor TB1, a class II TCP protein is expressed constitutively in maize because of the integration of Hopscotch transposable element upstream to its open reading frame. Thus TB1 expression occurs largely independent of the shade avoidance genetic apparatus that functions via phytochromes upstream of $t b 1$ gene. The TB1 protein of maize acts by binding to GGNCCC motifs in the promoter of its target genes. It has come to possess dual activity that of repressor for some genes and of activator for another class of genes. The molecular mechanism or cofactors, if any, that modulate the activity of TB1 as a repressor or an activator of genes remains to be determined.

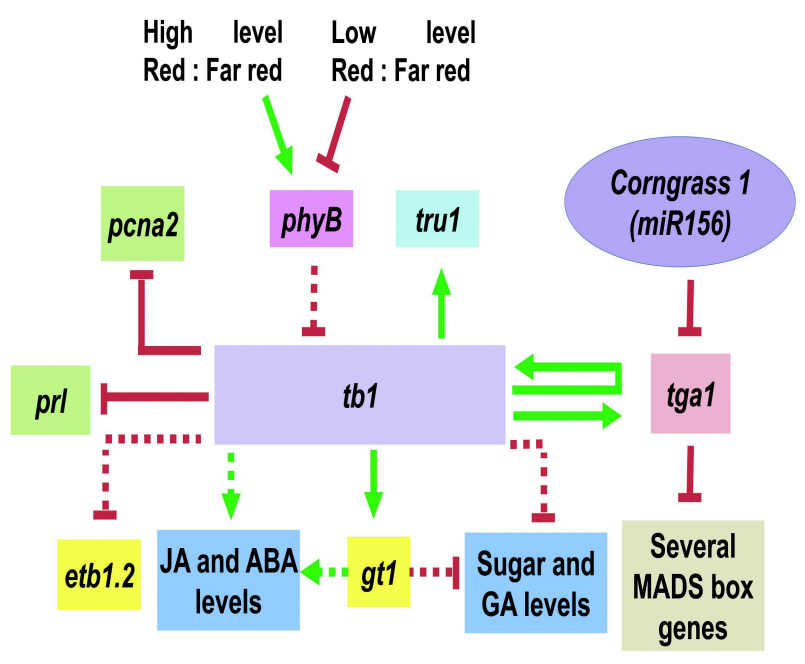

Fig. 2: Network of the domesticated allele of the gene $t b 1$ (teosinte branched 1). The solid or broken red and green lines, respectively, indicate repression and activation of the gene activity under the control of phy $B$ (phytochrome B), tb1 miR156 (microRNA 156) and gt1 (grassy tillers 1) and tga1 (teosinte glume architecture 1). The solid lines mean that the nature of interaction has been proved to be direct. The genes regulated by tb1 are: pcna2 (proliferating cell nuclear antigen 2) and prl(prolifera) that encode cell cycle determining proteins; etb1.2 (enhancer of tb1.2) a cis element of $\mathbf{Z m}$ YAB2.1 (Zea mays YABBY transcription factor 2.1); gt1 (grassy tillers 1) which encodes a homeodomain zipper transcription factor; tru1 (tassels replace upper ears1) which encodes a BTB/POZ ankyrin repeat transcription factor; and $\operatorname{tga} 1$. The genes $t$ b1 and $g t 1$ activate biosynthesis of inhibitory phytohormonesjasmonic acid (JA) and abscicic acid (ABA) and repress biosynthesis of growth stimulatory hormones gibberellins (GA) and pathway(s) associated with sugar availability. Several MADS-box transcription factors, including zag1 (zeaagamous 1), zag2, zmm3 (Zea mays MADS3), zmm19 and ZmMADS2 are repressed by tga1. In addition of $t b 1$, domestication process selected mutant alleles in etb1.2, gt1, tru1, tga1, and all the listed MADS-box genes/ loci. This figure is a modified version of the figure 5 of Studer et al. 2017 and figure 6 of Dong et al. 2019.

TB1 acts as the activator of several major effect genes: the gtl, tgal, and trul genes (Studer et al., 2017; Dong et al., 2017). TB1 is an activator of its own gene. TB1 activity reinforces GT1 expression which involves proll.1 allele upstream of gt 1 . TB1 and GT1 reduce sugar levels, increase levels of abscicic acid and jasmonic acid and reduce the concentrations of gibberellic acid and thereby contain branching. TRU1, activated by TB1 is part of the 
regulatory hub that makes tiller buds dormant (Dong et al., 2017 and 2019). Thus the strongly expressed TB1 and GT1 functions suppress initiation of secondary ears on maize plants. TB1 serves as the direct activator of $\operatorname{tg} a 1$, such that the downregulatory effect on tgal of miRNA156, the product of CORNGRASS1 gene which decreases the abundance of tgal transcripts, is minimal. The TGA1 protein because of a transversion mutation in it strongly represses a number of MADS-box transcription factor genes. Perhaps many other genes, yet to be identified are regulated by TGA1. The MADS-box genes zag1 (zeaagamous homolog 1), zag2, zmm3 (zea mays MADS3), zmm 19 and zmMADS2 have been shown to be repressed by TGA1. It is also known that the identified MADS-box genes have themselves undergone allelic changes to adapt to the repressive role of TGA1 in maize (Zhao et al. 2011). The roles of the MADS-box genes interactive with tgal gene remain to be revealed (Studer et al. 2017; and references therein).

TB1 protein represses the $Z m Y A B 2.1$ (a YABBY class transcription factor) gene by acting at the etb1.2 (enhancer of $t b 1$ ) locus upstream to it. Further, the $Z m Y A B 2.1$ gene underwent selection for a loss-offunction mutation during maize domestication. The two effects nullified the function of $Z m Y A B 2.1$ in elongation of internode length in the female inflorescence, thus permitting closely packed spiral phyllotaxy of ear internodes in the cobs of modern maize. TB1 has also been found to reduce the expression of cell cycle genes pcna 2 (proliferating cell nuclear antigen 2) and prl (prolifera) by binding to their promoters. Both pcna 2 and prl are involved in the control of DNA replication in floral organs. These genes do not show evidence of allelic change under the selection pressure of maize domestication (Studer et al. 2017).

Functional cataloguing of all the downstream target genes of major effect maize genes is desirable for designing of improved genetic pathways for higher yields in maize and related Poaceae crops. A pathway for exploiting tgal and its orthologs to improve maize has been outlined (Wei et al., 2018).

\section{Metabolome Changes Associated with Teosinte to Maize Domestication}

The domestication selection in teosinte led to evolvement of maize in which the grain size increased, grains became non-shattering, inflorescence bearing the grains increased in size with more grains and plant became less branched. These phenotypic changes involved major changes in gene expression profile of the whole plant. Comparison of seedling metabolomes of maize vs teosinte has revealed that the domestication process led to correlated reshaping of the metabolome. A total of 461 metabolites showed divergence; the divergent metabolites were largely alkaloids, terpenoids and lipids (Xu et al. 2019). These findings are suggestive of genetic changes in chloroplast and mitochondrial genomes in addition to the nuclear genome.

\section{Prospects of Deploying Polymorphisms at Zmtb1 and Zmtgal Genes and theirs Orthologs to Cause Agronomic Improvement in Cereals}

The archaeological, genetic and genomic studies have indicated that the process of domestication has been largely parallel in the cereals, including maize, rice wheat, barley, sorghum and pearl millet. The artificial selection exercised by early farmers $(12,000-4,000$ ya) on the wild parental subspecies/species of cereal crops was for the presence of the following kinds of domesticative traits: less vegetative growth and improved prolificacy (small number of grain-rich inflorescences), naked bold grains that did not disarticulate from the inflorescence spontaneously, and easiness in the harvesting of grain bearing inflorescences and in separation of grains from inflorescences (Salamini et al., 2002; Paterson et al., 2003; Fuller et al., 2014; Schilling et al., 2018). In maize, selection of the useful traits amounted to selection of recombinants carrying naturally induced mutant Zmtb1 and Zmtgal alleles, which imparted large majority of the desirable traits (Flint-Garcia 2017). There is evidence that genes orthologous to Zmtbl and Zmtgal are carried in multiple copies in cereals. For example, in addition to $\mathrm{Zmtbl}, B R A N C H$ ANGLE DEFECTIVE 1 (BADI) is the other cycloidea type class II TCP domain gene identified and characterized in maize (Bai et al. 2012). This class of genes characterized in rice are $O S T B 1$ and PROLIFERATING CELL FACTOR 1 (OsPCFI) and (OsPCF2) (Kosugi and Ohashi 1997; Nicolas and Cubas 2016). There are 30 orthologs of Zmtgal in maize and 16 orthologs of these in rice (Martin-Trillo and Cubas 2010). The $t b 1$ and tgal orthologs are 

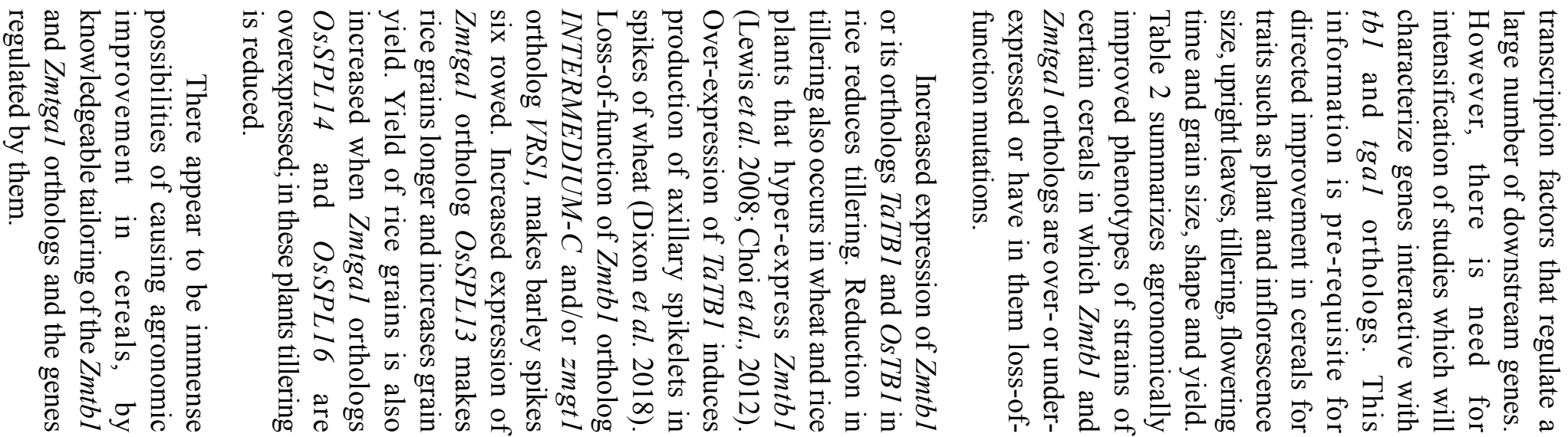

Table 2: Phenotypic effect of hyper- or hypo-expression or loss-of-function of orthologs of maize (Zea mays ssp. mays) teosinte branched (tb1), teosinte glume architecture 1 (tga1), grassy tillers 1 (gt1) and tassels replace upper-ears 1 (tru1) genes in cereals other than maize

\begin{tabular}{|c|c|c|c|c|c|}
\hline S.no. & Maize gene & Heterogous cereal species & Ortholog of maize gene & Phenotypic effect & References \\
\hline 1 & $Z m$ tbl & Triticum aestivum (wheat) & Ta TB1 & $\begin{array}{l}\text { Hyper-expression reduces tillering and stimulates production } \\
\text { of axillary spikelets on inflorescence }\end{array}$ & Dixon et al., 2018 \\
\hline 2 & & Oryza sativa (rice) & Os $T B 1$ & $\begin{array}{l}\text { Decreased expression increases tiller number and increased } \\
\text { expression reduces tillering and panicle number }\end{array}$ & Choi et al., 2012 \\
\hline 3 & & Hordeum vulgare (barley) & INTERMEDIUM-C(HvTB1) & $\begin{array}{l}\text { Loss-of-function plants produce inflorescences bearing six } \\
\text { rows of spikelets }\end{array}$ & Ramsay et al., 2011 \\
\hline 4 & & $\begin{array}{l}\text { Pennisetum glaucum } \\
\text { (pearl millet) }\end{array}$ & $P g t b 1$ & $\begin{array}{l}\text { The alleles } Z m t b l \text { and } P g t b l \text { have analogous phenotypic } \\
\text { effects }\end{array}$ & Ramigereaun et al. 2011 \\
\hline 5 & Zm tga 1 & Oryza sativa (rice) & Os SPL16/Os GW8 & $\begin{array}{l}\text { Over-expressing plants are dwarfer, have accelerated flwering, } \\
\text { bear panicles with lesser branching, have higher grain yield and } \\
\text { the grains produced are broader; loss-of-function plants } \\
\text { produce slender grains of better quality }\end{array}$ & Wang et al. 2012 \\
\hline 6 & & & Os SPL14 & $\begin{array}{l}\text { Increased expression is associated with less tillering, profuse } \\
\text { panicle branching and higher grain yield }\end{array}$ & Miura et al. 2010 \\
\hline 7 & & & Os SPL13 & Hyper-expression enhances grain length and overall grain yield & Si et al. 2016 \\
\hline 8 & Zm gtl & Hordeum vulgare (barley) & Hv VRS1 (Six-Rowed Spike 1) & Loss-of-function mutants produce six-rowed inflorescences & Komatsuda et al. 2007 \\
\hline 9 & Zm trul & & Hv CUL 4 (UNICULM-4) & $\begin{array}{l}\text { Loss-of-function mutants are ligule-less and demonstrate } \\
\text { decreased branching and tillering }\end{array}$ & Tavakol et al. 2015 \\
\hline
\end{tabular}

a, This phenotype is inverse of loss-of-function trul mutants in maize 
single nucleotide polymorphisms (SNPs) segregating in 17 accessions of parviglumis and 23 land races and 60 cultivars of maize (Wang et al., 2019) has revealed the following two highly important features of domesticative evolution of maize from teosinte, that may be common to domestication of other crops.

\section{Enrichment of Genome with AT-Nucleotides}

The genic and non-genic regions of all the chromosomes became AT enriched in maize as compared to teosinte. AT-enrichment was more pronounced in the non-genic segments of genome, such as in pericentromeric regions and transposable elements [which comprise $85 \%$ of the maize genome; bulk of them retrotransposons ( $>50 \%$ ), SanMaguel and Vitte 2009]. Segments of genome rich in methylated CG underwent especially high level of AT enrichment. Such intensified genomic divergence between teosinte and maize has been attributed to high mutability (via gene sequence change and transposon/ retrotransposon mutagenesis) trait of maize populations undergoing domesticative selection. The high mutability trait resulted from increase in the errors in repair of DNA damage caused by natural exposure to solar UV-radiation, particularly UV-B radiation. Haploid pollen is a highly sensitive target of UV-B radiation; in them transposons are known to get activated (Walbot 1999). The average AT content of major maize transposons is 52\% (SanMaguel and Vitte 2009). The selection of GC $\rightarrow$ AT mutations, in gene and non-gene DNA sequences genome-wide, led to enormous savings in energy, since production of GC base pairs requires much more energy than synthesis of AT base pairs (Ussery et al. 2009). It is observed that the saved energy, via AT enrichment of genome and low prolificative morphology, positively correlates with the observed high harvestibility of maize versus teosinte.

\section{Selection of Mutants in ATR Genes Led to Higher Mutability}

Genome wide association studies (GWAS) on the SNPs in the above mentioned 100 accessions (Wang et al. 2019) led to the finding that mutant alleles in ATR genes have been responsible for the high mutation rate in maize populations as compared to mutation rate in bulk of parviglumis populations. The ATR (Ataxia telangiectasia and RAD3 related, a serine/ threonine kinase) gene is known to regulate DNA damage response mechanisms by activating downstream gene products, including those involved in nucleotide excision repair (NER) (Hu et al., 2016). The ATR polymorphism observed in modern maize also existed in certain wild populations of teosinte. It is suggested that ATR mutant alleles were selected by early farmers, unknowingly, when they correlatively selected large effect mutant alleles in $t b 1$ and/or gt 1 plants based on morphology.

Parallelism has been noted between domestication of maize and soybean crops, in terms of AT enrichment of genome via the activity of ATR mutations selected during domestication (Wang et al., 2019). Since AT-enrichment saves energy, that is required to increase the yield of crops, high GC $\rightarrow$ AT mutability via errors in repair of UV-damage may be a common feature of domestication process, which is a special kind of evolution dependent on artificial selection of a network of genes which together determine the traits of low prolificacy and high harvestibilty.

\section{Concluding Remarks}

Domestication in maize involved selection of polymorphism in at least $1000(\sim 1400)$ loci distributed over its 10 chromosomes. Thus far some major effect domesticating alleles have been identified and characterized. All of these (tbl, tgal, trul, gtl, ral, zfll, zfl2, zagll and shl duplicates) have been found to encode transcription factors. Only a few of these large effect domesticating genes have been investigated for their downstream genes whose functions are responsible for the phenotype of domesticated maize. For example, some progress has been made in cataloguing of the networks of $t b 1, g t l$ and tgal genes. However, there is need to characterize the entire network of 1000 or so loci/ genes which underwent domesticating selection, by use of the available genetic-cum-genomic approaches. Each of the domesticating loci needs to undergo organ- and environment-wise expression, in its domesticating form and following incorporation of lossof-function mutations and introduction of RNA interferences and over-expressing polymorphisms. There is also need to characterize the metabolome changes in different plant organs that have been associated with domestication. 
Corresponding genetic-cum-genomic studies have also been in progress in other cereals, especially rice, wheat and sorghum, and a high degree of parallelism has been observed between the domesticating processes of cereals. Effects of the over-expressing domesticating maize genes should also be studied in heterologus cereals and vice-versa. The material and knowledge so gained will allow directed agronomic improvement in maize and cereals for gain in grain yield and produce of high quality.

Domestication of teosinte into maize has been found to have been driven by high mutability trait acquired via mutations in ATR genes. Transposon mutagenesis was most likely involved. These mutagenic mechanisms may have been responsible

\section{References}

Bai F, Reinheimer R, Durantini D, Kellogg E A and Schmidt R J (2012) TCP transcription factor, BRANCH ANGLE DEFECTIVE 1 (BAD1), is required for normal tassel branch angle formation in maize Proc Natl Acad Sci 109 12225-12230

Beadle G (1939) Teosinte and the origin of maize J Hered 30245 247

Bomblies K and Doebley J F (2006) Pleiotropic effects of the duplicate maize FLORICAULA/LEAFY genes zfll and zfl2 on traits under selection during maize domestication Genetics 172 519-531

Briggs W H, McMullen M D, Gaut B S and Doebley J (2007) Linkage mapping of domestication loci in a large maizeteosinte backcross resource Genetics 177 1915-1928

Brown P J, Upadyayula N, Mahone G S, Tian F, Bradbury P J et al. (2011) Distinct genetic architectures for male and female inflorescence traits of maize PLoS Genet 7 e1002383

Bush M B, Piperno D R and Cohnvaux P A (1989) A 6000 year history of Amazonian maize cultivation Nature 340303 305

Choi M S, Woo M O, Koh E B, Lee J, Ham T H, Seo H S and Koh H J (2012) Teosinte Branched 1 modulates tillering in rice plants Plant Cell Rep 31 57-65

Dixon L, Greenwood J, Bencivenga S, Zhang P, Cockram J, Mellers G, Ramm K, Cavanagh C, Swain S M and Boden S A (2018) TEOSINTE BRANCHED1 regulates inflorescence architecture and development in bread wheat (Triticumaestivum) Plant Cell 30 563-581 for the polymorphism observed at $<1000$ loci for domesticative genes in maize and for AT enrichment of entire maize genome, in comparison to teosinte. There is need to investigate whether enhanced spontaneous mutagenesis and AT-enrichment of genome have been among the features associated with domestication of cereals in general.

\section{Acknowledgements}

Grateful thank are due to the Director of NIPGR and Vice-Chancellor of JVWU and Head of its Innovation Center. SK wishes to thank Indian National Science Academy for the award of its honorary emeritus scientistship.

Doebley J and Iltis H H (1980) Taxonomy of Zea (Gramineae) I. A subgeneric classification with key to taxa American Journal of Botany 67 982-993

Doebley J and Stec A (1991) Genetic analysis of the morphological differences between maize and teosinte Genetics 129 285295

Doebley J and Stec A (1993) Inheritance of the morphological differences between maize and teosinte: comparison of results from two F2 populations Genetics 134 559-570

Doebley J, Stec A and Gustus C (1995) teosinte branched1 and the origin of maize: evidence for epistasis and the evolution of dominance Genetics 141 333-346

Doebley J, Stec A and Hubbard L (1997) The evolution of apical dominance in maize Nature 386 485-488

Dong Z, Li W, Unger-Wallace E, Yang J, Vollbrecht E and Chuck $\mathrm{G}$ (2017) Ideal crop plant architecture is mediated by tassels replace upper ears1, a BTB/POZ ankyrin repeat gene directly targeted by TEOSINTE BRANCHED1 Proc Natl Acad Sci USA 114 E8656-E8664

Dong Z, Xiao Y, Govindarajulu R, Feil R, Siddoway M L, Nielsen T, Lunn J E, Hawkins J et al. (2019) The regulatory landscape of a core maize domestication module controlling bud dormancy and growth repression Nature Communications $\mathbf{1 0}$ Article number: 3810

Flint-Garcia S A (2017) Kernel evolution: from teosinte to maize ARS.USDA.GOV

Fuller D Q, Derham T and Arroy-Kalin M (2014) Convergent evolution and parallelism in plant domestication revealed by an expanding archaeological record Proc Natl Acad Sci 


\section{USA 111 6147-6152}

Hufford M B, Bilinski P, Pyhajarvi T and Ross-Ibarra J (2012) Teosinte as a model system for population and ecological genomics Trends Genet 28 606-615

Iltis H H and Doebley J F (2006) Taxonomy of zea (Gramineae). II. Subspecific categories in the Zea mays complex and a generic synopsis Am J Bot 67994

Jaenicke-Despres V, Buckler E S, Smith B D, Gilbert M T P, Cooper A, Doebley J and Paabo S (2003) Early allelic selection in maize as revealed by ancient DNA Science $\mathbf{3 0 2}$ 1206-1208

Jiao Y, Peluso P, Shi J, Liang T, Stitzer M C, Wang B, Campbell M S, Stein J C, Wei X, Chin C S et al. (2017) Improved maize reference genome with single-molecule technologies Nature 546 524-527

Kennett D J, Thakar H B, Van Derwarker A M, Webster D L, Culleton B J, Harper T K, Kistler L, Scheffler T E and Hirth K (2017) High-precision chronology for Central American maize diversification from El Gigante rockshelter, Honduras Proc Natl Acad Sci 114 9026-9031

Kistler L, Yoshi Maezumi S, De Souza J G, Przelomska N A S, Costa F M, Smith O, Loiselle H, Ramos-Madrigal J, Wales N, Ribeiro E R et al. (2018) Multiproxy evidence highlights a complex evolutionary legacy of maize in South America Science 362 1309-1313

Komatsuda T, Pourkheirandish M, He C, Azhaguvel P, Kanamori H, Perovic D et al.(2007) Six-rowed barley originated from a mutation in a homeodomainleucine zipper I-class homeobox gene Proc Natl Acad Sci USA 104 1424-1429

Kosugi S and Ohashi Y (2002) DNA binding and dimerization specificity and potential targets for the TCP protein family Plant J 30 337-348

Kosugi S and Ohashi Y (2007) PCF1 and PCF2 specifically bind to $c i s$ elements in the rice proliferating cell nuclear antigen gene Plant Cell 91607

Lemmon Z H and Doebley J F (2014) Genetic dissection of a genomic region with pleiotropic effects on domestication traits in maize reveals multiple linked QTL Genetics 198 345-353

Lewis J M, Mackintosh C A, Shin S, Gilding E, Kravchenko S, Baldridge G, Zeyen R and Muehlbauer G J (2008) Overexpression of the maize Teosinte Branched 1 gene in wheat suppresses tiller development Plant Cell Rep 27 1217-1225

Lin Z, Li X, Shannon L M, Yeh C T, Wang M L, Bai G, Peng Z, Li J, Trick H N, Clemente T E et al. (2012) Parallel domestication of the Shatteringl genes in cereals Nat Genet
$44720-724$

Lopez A N A, de Jesus Sanchez Gonzalez J, Ruiz Corral J A, De La Cruz Larios L, Santacruz-Ruvalcaba F, Sanchez Hernández C V and Holland J B (2011) Seed dormancy in Mexican teosinte Crop Science 51 2056-2066

Lu Y, Hokin S A, Kermicle J L et al. (2019) A pistil-expressed pectin methylesterase confers cross-incompatibility between strains of maize Nat Commun 10 article no. 2304

Mangelsdorf P C and Reeves R G (1938) The origin of maize Proc Natl Acad Sci USA 24303

Martin-Trillo M and Cubas P (2010) TCP genes: a family snapshot ten years later Trends Plant Sci 15 31-39

Matsuoka Y, Vigouroux Y, Goodman M M, Sanchez G J, Buckler E and Doebley J (2002) A single domestication for maize shown by multilocus microsatellite genotyping Proc Natl Acad Sci 99 6080-6084

Minow M A A, Avila L M, Turner K, Ponzoni E, Mascheretti I, Dussault F M, Lukens L, Rossi V and Colasanti J (2018) Distinct gene networks modulate floral induction of autonomous maize and photoperiod-dependent teosinte $J$ Exp Bot 69 2937-2952

Miura K, Ikeda M, Matsubara A, Song X J, Ito M, Asano K, Matsuoka M, Kitano H and Ashikari M (2010) OsSPL14 promotes panicle branching and higher grain productivity in rice Nat Genet $\mathbf{4 2}$ 545-549

Nicolas M and Cubas P (2016) TCP factors: New kids on the signaling block Curr Opin Plant Biol 33 33-41

Paterson A H, Bowers J E, Peterson D G, Estill J C and Chapman B A (2003) Structure and evolution of cereal genomes Curr Opin Genet Dev 13 644-650

Piperno D R and Flannery K V (2001) The earliest archaeological maize (Zea mays L.) from highland Mexico: New accelerator mass spectrometry dates and their implications Proc Natl Acad Sci 98 2101-2103

Piperno D R, Holst I, Winter K and McMillan O (2015) Teosinte before domestication: Experimental study of growth and phenotypic variability in Late Pleistocene and early Holocene environments Quat Int 363 65-77

Piperno D R, Ranere A J, Holst I, Iriarte J and Dickau R (2009) Starch grain and phytolith evidence for early ninth millennium B.P. maize from the Central Balsas River Valley, Mexico Proc Natl Acad Sci 106 5019-5024

Preston J C, Wang H, Kursel L, Doebley J and Kellogg E A(2012) The role of teosinte glume architecture (TGA1) in coordinated regulation and evolution of grass glumes and inflorescence axes New Phytol 193 204-215

Ramos-Madrigal J, Smith B D, Moreno-Mayar J V, 
Gopalakrishnan S, Ross-Ibarra J, Gilbert M T P and Wales N (2016) Genome sequence of a 5,310-year-old maize cob provides insights into the early stages of maize domestication Curr Biol 26 3195-3201

Ramsay L, Comadran J, Druka A, Marshall D F, Thomas W T B, MacAulay M, MacKenzie K, Simpson C, Fuller J, Bonar $\mathrm{N}$ et al. (2011) INTERMEDIUM-C, a modifier of lateral spikelet fertility in barley, is an ortholog of the maize domestication gene TEOSINTE BRANCHED 1 Nat Genet 43 169-172

Remigereau M S, Lakis G, Rekima S, Leveugle M, Fontaine M C, Langin T, Sarr A and Robert T (2011) Cereal domestication and evolution of branching: Evidence for soft selection in the TB1 orthologue of pearl millet (Pennisetum glaucum [L.] R. Br.) PLoS One 6 e22404

Salamini F, Ozkan H, Brandolini A, Schafer-Pregl R and Martin W (2002) Genetics and geography of wild cereal domestication in the near east Nat Rev Genet 3 429-441

SanMaguel P and Vitte E (2009) The LTR retrotransposons of maize. In Handbook of Maize-Genetics and Genomics. (Bennetzen JL and Hake S ed.), Springer, New York 707727

Schilling S, Pan S, Kennedy A and Melzer R (2018) MADS-box genes and crop domestication: The jack of all traits $J \operatorname{Exp}$ Bot 69 1447-1469

Si L, Chen J, Huang X, Gong H, Luo J, Hou Q, Zhou T, Lu T, Zhu J, Shangguan Y, et al (2016) OsSPL13 controls grain size in cultivated rice Nat Genet $\mathbf{4 8}$ 447-456

Sigmon B and Vollbrecht E (2010) Evidence of selection at the ramosal locus during maize domestication Mol Ecol 19 1296-1311

Stitzer M C and Ross-Ibarra J (2018) Maize domestication and gene interaction New Phytol 220 395-408

Studer A, Zhao Q, Ross-Ibarra J and Doebley J (2011) Identification of a functional transposon insertion in the maize domestication gene tb1 Nat Genet 43 1160-1163

Studer A J and Doebley J F (2011) Do large effect QTL fractionate? A case study at the maize domestication QTL teosinte branched Genetics 188 673-681

Studer A J and Doebley J F (2012) Evidence for a natural allelic series at the maize domestication locus teosinte branched 1 Genetics 191 951-958

Studer A J, Wang H and Doebley J F (2017) Selection during maize domestication targeted a gene network controlling plant and inflorescence architecture Genetics 207 755-765

Tavakol E, Okagaki R, Verderio G, Shariati J V, Hussien A, Bilgic $\mathrm{H}$, Scanlon M J et al. (2015) The barley Uniculme 4 gene encodes a BLADE-ON-PETIOLE-like protein that controls tillering and leaf patterning Plant Physiol 168 164-174

Vigouroux Y, McMullen M, Hittinger CT, Houchins K, Schulz L, Kresovich S, Matsuoka Y and Doebley J (2002) Identifying genes of agronomic importance in maize by screening microsatellites for evidence of selection during domestication Proc Natl Acad Sci 99 9650-9655

Vollbrecht E, Springer P S, Goh L, Buckler IV E S and Martienssen R (2005) Architecture of floral branch systems in maize and related grasses Nature 436 1119-1126

Walbot V (1999) UV-B damage amplified by transposons in maize Nature 397 398-399

Wang B, Tseng E, Regulski M, Clark T A, Hon T, Jiao Y, Lu Z, Olson A, Stein J C and Ware D (2016) Unveiling the complexity of the maize transcriptome by single-molecule long-read sequencing Nat Commun 711708

Wang H, Nussbaum-Wagler T, Li B, Zhao Q, Vigouroux Y, Faller M, Bomblies K, Lukens L and Doebley J F (2005) The origin of the naked grains of maize Nature 436 714-719

Wang H, Studer A J, Zhao Q, Meeley R and Doebley J F (2015) Evidence that the origin of naked kernels during maize domestication was caused by a single amino acid substitution in tgal Genetics 200 965-974

Wang J, Li X, Kim K D et al. (2019) Genome-wide nucleotide patterns and potential mechanisms of genome divergence following domestication in maize and soybean Genome Biol 2074

Wang S, Wu K, Yuan Q, Liu X, Liu Z, Lin X, Zeng R, Zhu H, Dong G, Qian Q et al (2012) Control of grain size, shape and quality by $O S S P L 16$ in rice Nat Genet 44 950-954

Watling J, Shock M P, Mongelo G Z, Almeida F O, Kater T, De Oliveira P E and Neves E G (2018) Direct archaeological evidence for Southwestern Amazonia as an early plant domestication and food production centre PLoS One $\mathbf{1 3}$ e0199868

Weber A L, Briggs W H, Rucker J, Baltazar B M, SanchezGonzalez J D J, Feng P, Buckler E S and Doebley J (2008) The genetic architecture of complex traits in teosinte (Zea mays ssp. parviglumis): New evidence from association mapping Genetics 180 1221-1232

Wei H, Zhao Y, Xie Y and Wang H (2018) Exploiting SPL genes to improve maize plant architecture tailored for high-density planting $J$ Exp Bot 69 4675-4688

Whipple C J, Kebrom T H, Weber A L, Yang F, Hall D, Meeley R, Schmidt R, Doebley J, Brutnell T P and Jackson D P (2011) Grassy Tillers1 promotes apical dominance in maize and responds to shade signals in the grasses Proc 
Natl Acad Sci 108 E506-E512

Wills D M, Fang Z, York A M, Holland J B and Doebley J F (2018) Defining the role of the MADS-box gene, Zea Agamous-like1, a target of selection during maize domestication $J$ Hered 109 333-338

Wills D M, Whipple C J, Takuno S, Kursel L E, Shannon L M, Ross-Ibarra J and Doebley J F (2013) From many, one: genetic control of prolificacy during maize domestication PLoS Genet 9 e 1003604

Xu G, Cao J, Wang X, Chen Q, Jin W, Li Z ang Tian F (2019) Evolutionary metabolomics identifies substantial metabolic divergence between maize and its wild ancestor, teosinte The Plant Cell 31 1990-2009

Yang C J, Kursel L E, Studer A J, Bartlett M E, Whipple C J and Doebley J F (2016) A gene for genetic background in Zea mays: Fine-mapping enhancer of teosinte branched 1.2 to a yabby class transcription factor Genetics 204 1573-1585

Yang C J, Samayoa L F, Bradbury P J, Olukolu B A, Xue W, York A M et al. (2019) The genetic architecture of teosinte catalyzed and constrained maize domestication Proc Natl Acad Sci USA 116 5643-5652

Zeder M A, Emshwiller E, Smith B D and Bradley D G (2006) Documenting domestication: the interaction of genetics and archaeology Trends in Genet 22 139-155

Zhao Q, Weber A L, McMullen M D, Guill K and Doebley J (2011) MADS-box genes of maize: frequent targets of selection during domestication Genet Res (Camb) 93 6575

Ussery D W, ýWassenaar T M and ýBorini S (2009) Computing for comparative microbial genomics Springer, London. 